\title{
MODELO MATEMÁTICO PARA AVALIAÇÃO DE QUALIDADE DE RESTAURANTE
}

\author{
Erica de Souza Fernandes \\ Universidade Estácio de Sá \\ Ericafenandes91@gmail.com \\ Marcelo Prado Sucena \\ Universidade Estácio de Sá \\ marcelosucena@gmail.com \\ Wanice Tostes Ribeiro Nogueira
Universidade Estácio de Sá
wanicetostesribeiro@gmail.com
}

RESUMO

Este trabalho teve como principal objetivo a criação de um modelo matemático com orientação da Inteligência Artificial, com a finalidade de avaliar o desempenho do estabelecimento comercial de alimentos. Foi necessário desenvolver análise bibliográfica sobre formas de avaliar desempenho do restaurante, para identificação de métricas que são utilizadas como variáveis de entrada do modelo matemático. Os métodos utilizados para modelagem, que são contidos na área Inteligência Artificiais, foram a Teoria Fuzzy e a Rede Neurais Artificiais. $\mathrm{O}$ modelo permite gerar 5 indicadores parciais e um final, denominado Indicador de Percepção do Cliente (IPC), que congrega todas as variáveis de entrada do modelo matemático. $\mathrm{O}$ modelo foi implementado no aplicativo Microsoft Excel, tendo como estudo de caso um restaurante "a lá carte", para exemplificar e validar o modelo. Após a coleta de dados, os seguintes resultados foram obtidos dentro de uma escala de zero a dez, sendo zero a pior situação e dez a melhor. $O$ resultado mostrou que há avaliação positiva para empresa, objeto de estudo de caso, porém constatando a necessidade de melhoras para o aumento do IPC.

Palavras-Chave: Teoria Fuzzy, Redes Neurais Artificiais, Avaliação de Desempenho, Modelo Matemático.

\begin{abstract}
The main objective of this work was the creation of a mathematical model with Artificial Intelligence orientation, with the purpose of evaluating the performance of the commercial food establishment. It was necessary to develop bibliographic analysis on ways to evaluate restaurant performance, to identify metrics that are used as input variables of the mathematical model. The methods used for modeling, which are contained in the Artificial Intelligence area, were the Fuzzy Theory and the Artificial Neural Network. The model allows to generate 5 partial indicators and a final one, called Customer Perception Indicator
\end{abstract}


(CPI), which brings together all the input variables of the mathematical model. The model was implemented in Microsoft Excel application, having as a case study a restaurant "a la carte", to exemplify and validate the model. After data collection, the following results were obtained within a scale from zero to ten, with zero being the worst situation and ten being the best. The result showed that there is a positive assessment for the company, object of case study, but noting the need for improvements to increase the CPI.

Keywords: Fuzzy Theory, Artificial Neural Networks, Performance Evaluation, Mathematical Model. 


\section{INTRODUÇÃO}

Levando em consideração o mercado competitivo que nos cerca na esfera global, empreendedores vêm cada vez mais buscar ferramentas de inovação para atuar e permanecer no cenário comercial.

Recentemente, tem-se constatado que o serviço com qualidade tornou-se um grande diferenciador no que se refere à competitividade comercial. Mediante as constantes mudanças no cenário econômico e na comercialização de produtos se faz necessário ingressar no âmbito onde os consumidores determinam o tipo de bens e serviços que estão dispostos a pagar. Haja vista que essa reciclagem, por parte dos empreendedores, é primordial para que a clientela permaneça assídua e fiel aos seus fornecedores. Hoje, compreendemos que grande parte de estabelecimentos comerciais vêm oferecendo aos seus clientes, além de mercadorias, excelência na qualidade da prestação de serviços, na tentativa de atingir um público maior, superar suas expectativas e criar uma carteira de pessoas fidedignas. (RODRIGUES, 2016).

Partindo desse pressuposto pode-se dizer que a formação de um novo perfil de cliente deixou cair por terra uma sociedade em que visava o lucro imediato e custo baixo. Dessa forma, as empresas que fizerem do serviço bem prestado sua força motriz serão aquelas que a médio ou longo prazo terão maior probabilidade de superar a concorrência e, por conseguinte, atuarão no ramo mercadológico com mais força e garantia de sucesso pleno. (SILVA, 2009)

De acordo com Moraes (2015), a fidelização do cliente e tão importante quanto atrailo, alguns motivos podem comprovar tal afirmação, tais como: o receptor fidedigno retorna ao local, as indicações por parte do consumidor tornam-se espontâneas e constantes, aumenta-se o valor do consumo, a receita se torna previsível e o "feedback" passa a ser de caráter preciso e honesto.

É interessante frisar que também podemos constatar que há um grande desafio em alcançar e conservar o padrão de qualidade que os usuários aspiram. Infelizmente, ainda encontramos na era globalizada empresas que adotam um padrão de administração com conceitos obsoletos, enquanto outras instituições procuram a perfeição, ou algo bem próximo a isso, a fim de serem capazes no emprego de seus serviços finais.

De acordo com Junior (2016), outro ponto relevante é que algumas organizações buscam formas de apontar e qualificar a qualidade de seus serviços dentro do cenário da atividade econômica em áreas distintas, inclusive no ramo alimentício. Podem-se citar autores, estudiosos e filósofos que discursam sobre Qualidade, competitividade, custo, benefícios entre outros assuntos pertinentes ao atendimento com excelência, mas ainda encontramos dificuldades em identificar fontes que trazem conteúdos que verbalizam modelos, padrões, etapas, aplicações etc., voltadas ao tema serviços, particularmente no setor de alimentos.

Para Berg (2018), o cliente é o motivo da existência de uma empresa e, desta forma é releve entendê-lo, reconhecendo suas motivações, pois ele sempre terá atitudes apenas no sentido de atender suas próprias inclinações e desejos.

Portanto, sendo conhecido o crescimento das exigências do mercado, a recombinação das classes, a dissipação de informações e a suma importância entender a percepção do cliente sobre o desempenho e a qualidade do serviço corporativo prestado.

Sendo assim, ao final desse estudo pretende-se chegar a um modelo matemático, usando a preceitos da Inteligência Artificial, para se determinar o desempenho de estabelecimento comercial no ramo alimentício.

Segundo Costa, Santana e Trigo (2015), uma gestão de qualidade é de grande importância para as instituições comerciais, uma vez que os clientes só conseguem mensurar a 
eficiência de determinado espaço após adquirir e utilizar os seus produtos: organização, ambiente, serviços, localidade, preço baixo etc., A partir do momento que uma organização se diversifica e acompanha as mudanças do empreendedorismo moderno torna-se mais acessível às vias de acesso e a relação direta com o público consumidor. Dessa forma, é mais provável que obtenha um "feedback" positivo.

É nesse contexto que podemos presumir a importância da temática proposta neste trabalho em avaliar o desempenho e satisfação dos bens e serviços oferecidos nas organizações através de métricas para o controle de desempenho e de qualidade do serviço prestado. Serão utilizados os conceitos de Inteligência Artificial para criação do modelo matemático oferecendo apoio a tomada de decisões tendo por base fatos reais, conhecimento empírico e teórico. Nesse sentido pode-se fazer uma análise mais apurada, tal como buscar o aperfeiçoamento da relação entre fornecedores e fregueses. Além disso, possibilitar a oferta de materiais e, consequentemente, maximizar sua colocação no mercado competidor. 


\section{METODOLOGIA}

Para a elaboração do Trabalho de Conclusão de Curso se seguirá a metodologia de caráter descritivo e avaliação qualitativa tendo por base a pesquisa bibliográfica.

Inicialmente, consultar-se-ão as fontes a partir de artigos, livros, periódicos científicos, tal como a observação, coleta de dados e aplicação do Método Fuzzy no espaço gastronômico.

Para Gil (2009), o objetivo principal da pesquisa descritiva é determinar a população, fenômeno ou estabelecimento das relações variáveis. Dos diversos estudos sobre esse tipo de investigação as características de maior relevância estão no uso de técnicas padronizadas a partir da coleta de dados, como por exemplo, o nível de atendimento em empresas de uma comunidade. Como também incluir opiniões, relações interpessoais, entre outros aspectos.

Após desenvolver a lógica matemática será fundamental a ilustração e utilização de seu uso, tal como validar os dados apurados dentro do estabelecimento comercial.

Em relação à pesquisa descritiva tem por viés retratar as características pertinentes às relações entre os clientes e a organização.

Sendo assim, pode-se estabelecer a fundamentação teórica e os resultados coletados em relação à questão da avaliação do desempenho comercial do ramo alimentício.

Para orientar o desenvolvimento deste TCC no intuito de se atingir os objetivos, se seguirão os seguintes passos:

1. Desenvolver estudo teórico sobre. Desempenho de estabelecimentos comerciais no ramo alimentício, conjunto Fuzzy, rede neural artificial e rede neuro-Fuzzy.

2. Pesquisar o estado da arte sobre formas de avaliar desempenho de estabelecimento comercial, de forma geral, além de estudos do ramo alimentício. Este item deve destacar os objetivos de cada estudo, além dos métodos e métricas usadas;

3. Baseando-se nas métricas definidas no item anterior serão estruturadas as variáveis de entrada Fuzzy do modelo matemático, tomando-se o universo de discurso, funções de pertinência e termos linguísticos associados;

4. Estrutura a Rede Neural Artificial necessária para se obter um indicador que represente o desempenho de estabelecimentos comerciais no ramo alimentício;

5. Implementar a Rede Neural Artificial, com seus neurônios artificiais, em Software;

6. Desenvolver estudo de caso:

6.1. Coletar e analisar dados por pesquisa com os clientes;

6.2. Agrupar as respostas dos clientes;

6.3. Processar dados agrupados no modelo matemático;

6.4. Analisar resultados. 


\section{BASE TEÓRICA}

\subsection{DESEMPENHO De ESTABELECIMENTOS COMERCIAIS No RAMO ALIMENTÍCIO}

A medição de desempenho é um fator dominante para a conversão da competitividade das empresas no cenário econômico atual, servindo de apoio para ferramentas de melhoria de produção e qualidade, tendo como objetivo o atingir a excelência no negocio.

Uma gama de investidores tem procurado inovar no mercado comercial para adquirir e, posteriormente, fidelizar seus consumidores. As organizações voltadas à prática de comercialização precisam entender que atender clientes é atender indivíduos e suas especificidades, conforme pontua Silva (2010).

Para Cabral (2015) o que diferencia uma empresa de outra no mercado competitivo é a excelência no atendimento. E quando uma gestão empresarial, juntamente com os profissionais atuantes da área, consegue maximizar a qualificação de um produto (desde a produção à entrega) aumenta a probabilidade de retorno e fidelização de seu cliente.

Na concepção de Goleman (2016), o fator fundamental para as instituições é a qualidade dos serviços prestados, pois evidencia o desenvolvimento de um trabalho bem feito. Estar atento, ouvir, reciclar, reformular, entre outras características, agrega valores e fortalece a empresa. Potencializar o atendimento é também garantir a satisfação pessoal para a organização, tal como para o público que queremos atingir. A partir daí, as dificuldades podem ser contornadas e minimizadas ao longo do processo produtivo.

Segundo Bortoluzz e col. (2012), as instituições comerciais necessitam de ferramentas que possam fazer um acompanhamento a curto ou médio prazo de seu funcionamento e assim, estabelecer estratégias para atuar no cenário competitivo igualitariamente com outros empreendimentos. O conceito de avaliação de desempenho organizacional, segundo alguns pesquisadores, traz como parâmetro o aperfeiçoamento de sistemas ou organizações como mote central. Nesse sentido, a classificação performática, geralmente, seguem padrões baseados em quatro perspectivas, a saber: financeira, clientes, processos internos e aprendizado e crescimento. Esses critérios e avaliações a serem executados determinam os objetivos, a viabilidade, promovem "feedback" ao avaliador, elaboram planos de ação e eliminam obstáculos.

Tazinasso e col. (2012), afirma que as instituições que tem por objetivo implantar um gerenciamento voltado ao atendimento perfeito devem estabelecer um procedimento de medição e análise que leve em consideração não apenas o lucro e redução de custo, mas sim uma gestão estratégica.

Assim, torna-se imprescindível uma apuração com viés financeiro (e não financeiro), tal como o levantamento de indícios à luz de aspectos distintos relacionados ao ambiente e desenvoltura de uma organização.

Junior (2016) pontua que os indicadores de qualidade são apenas um instrumento para monitorar e controlar o rendimento de uma empresa, no que se refere à eficácia e procura de seus objetivos de forma aprofundada e organizada. A definição de qualidade é realizada de acordo com cada negócio específico que englobam a área de atuação e os fundamentos e metas presentes, contanto que sempre sejam objetivos, ou seja, baseados em fatos reais.

Mediante os descritos acima, pode-se dizer que as informações coletadas e analisadas para validação de uma lógica operacional analisam as especificidades, expectativas e questões relacionadas aos clientes: ambiente, infraestrutura, espaço, cardápio, preço, estacionamento etc., 
Os estudos que abordam o desempenho e de qualidade em estabelecimentos comerciais são relativamente ecléticos quanto aos métodos usados. Nessa linha destacam-se os trabalhos de GARCEZ, FACHIN e ANDRADE (2000), MOURA e ALLIPRANDINI (2004), TINOCO e RIBEIRO (2007), FURTADO (2008), BRAGA, PEREIRA e JUNIOR (2015), AZEVEDO, COSTA e FREITAS (2015), SHICA, ALBUQUERQUE, SANTANA e ARAÚJO (2016).

$\mathrm{Na}$ visão de se tratar de unidades produtivas de alimentação como próximas de seus clientes finais, usando várias abordagens significativas para melhor compreensão de seus perfis, foram identificados os trabalhos de WOLFF (2005), SEKIYA (2013) e DEMOLINARI (2014).

Todos os estudos denotaram o esforço para se melhorar a relação entre restaurantes e seus clientes, bem como a minimização de custos, otimização de mão de obra, além do aumento da demanda, fator impulsionador da receita desses estabelecimentos. Os trabalhos investigados serviram também para identificação de atributos fundamentais para se mensurar qualidade e desempenho de restaurantes. O resumo deles está exposto na Tabela 1.

Tabela 1 - Relação entre Métricas e Autores da Revisão Bibliográfica 


\begin{tabular}{|c|c|c|c|c|c|c|c|c|c|c|c|}
\hline 30 & & & & DEJ & EIRC & $\mathrm{J}, \mathrm{BF}$ & SIL - & $\begin{array}{l}\text { ALE } \\
\text { SAO }\end{array}$ & $\mathrm{ENC}$ & VEMB & $\begin{array}{l}\text { IARINHA } \\
\text { DE } 2019\end{array}$ \\
\hline AUTORES/MÉTRICAS & 1 & 2 & 3 & 4 & 5 & 6 & 7 & 8 & 9 & 10 & FREQ \\
\hline ACESSO RESTAURANTE & & $\mathrm{x}$ & $x$ & & $\mathrm{x}$ & & & & & $\mathrm{x}$ & 4 \\
\hline ADAPTABILIDADE & & & & & & & $x$ & & & $\mathrm{x}$ & 2 \\
\hline AMBIENTE & $x$ & & $\mathrm{x}$ & & $x$ & $x$ & & $x$ & $x$ & $\mathrm{x}$ & 7 \\
\hline APRESENTAÇÃO DAS REFEIÇÕES & & & $\mathrm{x}$ & $x$ & & $\mathrm{x}$ & & & & $\mathrm{x}$ & 4 \\
\hline APRESENTAÇÃO DOS FUNCIONÁRIOS & & & $\mathrm{x}$ & & & & & $\mathrm{x}$ & $x$ & & 2 \\
\hline ARRANJO FISICO & & & & & & & & $x$ & & $\mathrm{x}$ & 2 \\
\hline ATENDIMENTO & $\mathrm{x}$ & $\mathrm{x}$ & $\mathrm{x}$ & $\mathrm{x}$ & & $\mathrm{x}$ & $\mathrm{x}$ & & $x$ & & 7 \\
\hline BARULHO & & & & & & $\mathrm{x}$ & & & $\mathrm{x}$ & $\mathrm{x}$ & 3 \\
\hline BEBIDA & $\mathrm{x}$ & $\mathrm{x}$ & & & & & & & & & 2 \\
\hline CARDAPIO & $\mathrm{x}$ & & & & & $\mathrm{x}$ & & $\mathrm{x}$ & & & 2 \\
\hline COMIDA REGIONAL & & & & & & & & & & $\mathrm{x}$ & 1 \\
\hline CONFORTO DAS CADEIRAS & & & & & & & & & & $\mathrm{x}$ & 1 \\
\hline CONHECIMENTO DAS TAREFAS PARTE DOS FUNCIONÁRIOS & & $\mathrm{x}$ & & & & & $\mathrm{x}$ & & $\mathrm{x}$ & & 3 \\
\hline DECORAÇÃO & $\mathrm{x}$ & $\mathrm{x}$ & & & & $\mathrm{x}$ & & & & & 3 \\
\hline DISPONIBILIDADE DO PLAY GROUD & & $\mathrm{x}$ & & & & & & & & & 1 \\
\hline ESPAÇO & & & & & & $\mathrm{x}$ & & & & & 1 \\
\hline ESTADO DE CONSERVAÇÃO DO RESTAURANTE & & $\mathrm{x}$ & & & & & & & & & 1 \\
\hline ESTACIONAMENTO & & & & & $\mathrm{x}$ & & & & & & 1 \\
\hline EVENTOS & & & $\mathrm{x}$ & & & & & & & & 1 \\
\hline EXPECTATIVAS PREVIAS & $\mathrm{x}$ & & & & & & & & & & 1 \\
\hline FORMA DE PAGAMENTOS & & & $\mathrm{x}$ & & & & & & & & 1 \\
\hline IMAGEM DA EMPRESA & & $\mathrm{x}$ & & & & & & & & & 1 \\
\hline NIVEL DE COMPRA & & & $\mathrm{x}$ & & & & $x$ & & $\mathrm{x}$ & & 3 \\
\hline INSTALAÇÃO DE APOIO & $\mathrm{x}$ & & & & & & & & & & 1 \\
\hline LIMPEZA & $\mathrm{x}$ & $\mathrm{x}$ & $x$ & & & $x$ & & & $\mathrm{x}$ & & 5 \\
\hline PREÇO & & & & & $\mathrm{x}$ & $\mathrm{x}$ & $x$ & & $\mathrm{x}$ & & 4 \\
\hline PRIVACIDADE & $\mathrm{x}$ & $\mathrm{x}$ & & & & & & & & & 2 \\
\hline PROMOÇÃO & & & & $\mathrm{x}$ & & & & & & & 1 \\
\hline QUALIDADE DA CLIMATIZAÇÃO & & & & & & $\mathrm{x}$ & & $x$ & $x$ & $\mathrm{x}$ & 4 \\
\hline QUALIDADE DA COMIDA & $\mathrm{x}$ & $\mathrm{x}$ & $\mathrm{x}$ & $x$ & $\mathrm{x}$ & & & & & $\mathrm{x}$ & 6 \\
\hline QUALIDADE NUTRICIONAL & & & & & & & & & $\mathrm{x}$ & & 1 \\
\hline QUANTIDADES DA PORÇÃO & $x$ & & & & & $x$ & & & & & 1 \\
\hline RAPIDEZ NO PAGAMENTO & & & & $x$ & & & & & $\mathrm{x}$ & & 2 \\
\hline RAPIDEZ EM SERVIR & & & & $\mathrm{x}$ & & & $x$ & & & & 2 \\
\hline SERVIÇOS OFERECIDOS & & $x$ & & & & & $x$ & & & & 2 \\
\hline VARIEDADE DAS REFEIÇÕES & & & & & $\mathrm{x}$ & $x$ & & & & & 2 \\
\hline VISTA DO RESTAURANTE & & $x$ & & & & & & & & & 1 \\
\hline
\end{tabular}

Legenda dos Autores: 1- TINOCO e RIBEIRO (2007); 2- FURTADO (2008); 3DEMOLINARI (2014); 4- WOLFF (2005); 5- BRAGA e Col (2015); 6- MOURA e ALLIPRANDINI (2004); 7-AZEVEDO e Col (2015); 8-GARCEZ e Col (2000); 9SEKIYA(2013); 10-SHICA e Col (2016).

\subsection{TEORIA NEURO-FUZZY}

O conceito Fuzzy pode ser compreendido como uma ocasião em que não é possível responder apenas "sim" ou "não". Mesmo sabendo-se sobre as informações necessárias, tratar de algo entre "sim" e "não", como "talvez" ou "quase", pode ser mais adequado. Em poucas palavras pode-se entender o conceito Fuzzy como um universo de inúmeras alternativas entre "sim" ou "não" para uma única pergunta. (OLIVEIRA 2004)

A Teoria Fuzzy se qualificou a partir da publicação do artigo intitulado Fuzzy Sets na 
revista Information and Control, por Zadeh (1965) afirma que uma das grandes vantagens da Lógica Fuzzy é a de realizar, por meio das propriedades dos conjuntos Fuzzy, a tradução de termos linguísticos utilizados nas comunicações diárias (linguagem natural) em expressões matemáticas.

Para Ross (1995), em conjuntos clássicos (crisp), a transição de um determinado elemento em um universo entre ser membro e não-membro de um dado conjunto é abrupta e bem-definida. Para um elemento em um universo que contém conjuntos Fuzzy, essa transição pode ser transcrita de modo a que possa ser considerada a fronteira subjetiva que existe entre o pertencer e o não-pertencer a um dado conjunto. Assim, um conjunto Fuzzy é um conjunto de elementos que têm vários níveis de participação no conjunto.

Ainda, segundo Ross (1995), tomando-se U como o Universo de Discurso, A como um subconjunto de $\mathrm{U}$ e $\mathrm{x}$ sendo um elemento de $\mathrm{U}$, tem-se que a função característica $\mu \mathrm{A}(\mathrm{x})$ é uma estrutura do conjunto universo no conjunto $[0,1]$. Essa função característica discrimina entre todos os elementos de $\mathrm{U}$ aqueles que, segundo algum critério, pertencem ou não ao subconjunto A.

Souza (2010) pontua que para se obterem os conjuntos Fuzzy generaliza-se a função característica da lógica clássica para o intervalo $[0,1]$, ou seja, $\mu \mathrm{A}(\mathrm{x}): \mathrm{U} \rightarrow[0,1]$, o que implica em considerar um contínuo de valores de pertinência e não apenas pertence (1) e não pertence (0). O elemento x pertencerá ao subconjunto A com um grau de pertinência que é um valor no intervalo $[0,1]$.

Em última análise, um conjunto Fuzzy é caracterizado por uma função de pertinência, e o grau de pertinência pode ser considerado como uma medida que expressa a possibilidade de que um dado elemento seja membro de um conjunto Fuzzy. Tais funções podem ser de diferentes formas, sendo as mais comuns as triangulares e trapezoidais, devido a facilidade de modelagem (GONÇALVES, 2007). As figuras 1 e 2 apresentam, respectivamente, as funções de pertinência triangular e trapezoidal.

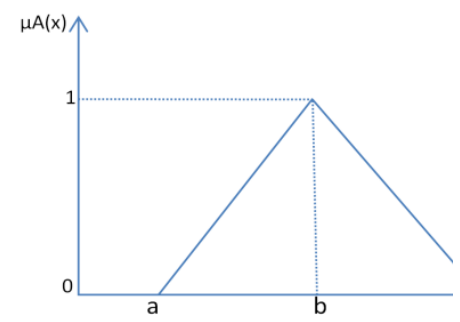

$$
\mu \mathrm{A}(\mathrm{x})=\left\{\begin{array}{c}
0 \text { for } \mathrm{x}<a . \\
\frac{\mathrm{x}-\mathrm{a}}{\mathrm{b}-\mathrm{a}} \text { for } \mathrm{a} \leq \mathrm{x} \leq \mathrm{b}, \\
\frac{\mathrm{c}-\mathrm{x}}{\mathrm{c}-\mathrm{b}} \text { for } \mathrm{b} \leq \mathrm{x} \leq \mathrm{c}, \\
0 \text { for } \mathrm{x}>c
\end{array}\right.
$$

Figura 1 - Função de Pertinência Triangular Fonte: Adaptado de Sanches (2009)

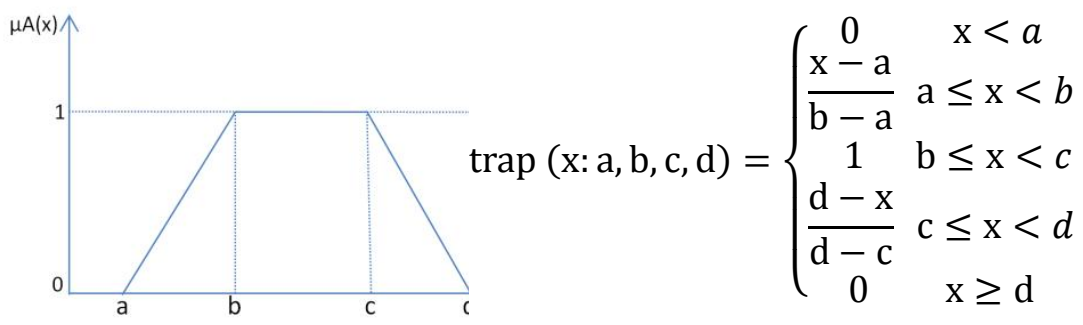

Figura 2 - Função de Pertinência Trapezoidal

Fonte: Adaptado de Sanches (2009) 
De acordo com Gomide, Gudwin e Tanscheit (2014), um sistema de inferência Fuzzy típico apresenta entradas não Fuzzy que são incluídas em certo universo de discurso, que caracterizam o mundo real, que são transformadas para o mundo Fuzzy, podendo se tomar decisões e criar ações de controle e consiste nos seguintes elementos:

- Fuzzyficação: as variáveis linguísticas são definidas e analisadas no mundo real, sendo Fuzzyficadas por intermédio das funções de pertinência em cada conjunto Fuzzy;

- Inferência: processo de avaliação de cada variável entrada após a Fuzzyficação que permite a associação do conhecimento por meio de associações previamente definidas;

- DeFuzzyficação: processo de interpretação do conjunto Fuzzy de saída utilizado após a inferência, convertida para um valor numérico Real que representa um número real. Ainda segundo Gomide, Gudwin e Tanscheit (2014), não há nenhum procedimento sistemático para a escolha da DeFuzzyficação, podendo ser feita por vários métodos, sendo o mais comum o do "centro dos máximos", que é baseado na média ponderada das entradas pelos seus respectivos graus de pertinência.

As Redes Neurais Artificiais (RNA) são procedimentos baseados no desempenho do cérebro e do sistema nervoso humano. Tradicionalmente têm sido utilizadas para repetir tarefas cognitivas, sendo utilizadas como protótipos computacionais que apresentam capacidade de obtenção do conhecimento (baseado em informações oferecidas pelo ser humano) e podem ser determinadas como um conjunto de unidades de procedimentos, definidas por neurônios artificiais interligados por um grande número de conexões (sinapses artificiais), sendo reproduzidos por vetores/matrizes de pesos sintéticos. (SILVA 2010).

Segundo Savot (2002), as estruturas das Redes Neuro-Fuzzy, que usam conceitos das Teoria Fuzzy e de RNA, reúnem as características do raciocínio da Lógica Fuzzy com a capacidade de processamento em paralelo das Redes Neurais Artificiais.

De acordo com Ortega (2001), uma das primeiras arquiteturas Neuro-Fuzzy intitulada Sistema de Inferência Adaptativo Neuro-Difuso (ou ANFIS - Adaptative Neural Fuzzy Inference System), foi proposta por Jang em 1993, e considera que o processamento neuronal é baseado em sistema de inferência Fuzzy. 


\section{MODELO E ESTUDO DE CASO}

Após a revisão bibliográfica apresentada no item 2.1 treze métricas foram selecionadas para representar as variáveis de entrada do modelo matemático, que são: condição do mobiliário, temperatura ambiente, ruído ambiente, estacionamento para clientes, disponibilidade de transporte público, acessibilidade para movimentação de clientes, preço, apresentação geral, sabor do alimento, apresentação dos funcionários, rapidez no pagamento, rapidez no serviço e limpeza do ambiente. Tais métricas foram transformadas em variáveis Fuzzy segundo consta a Figura 3.

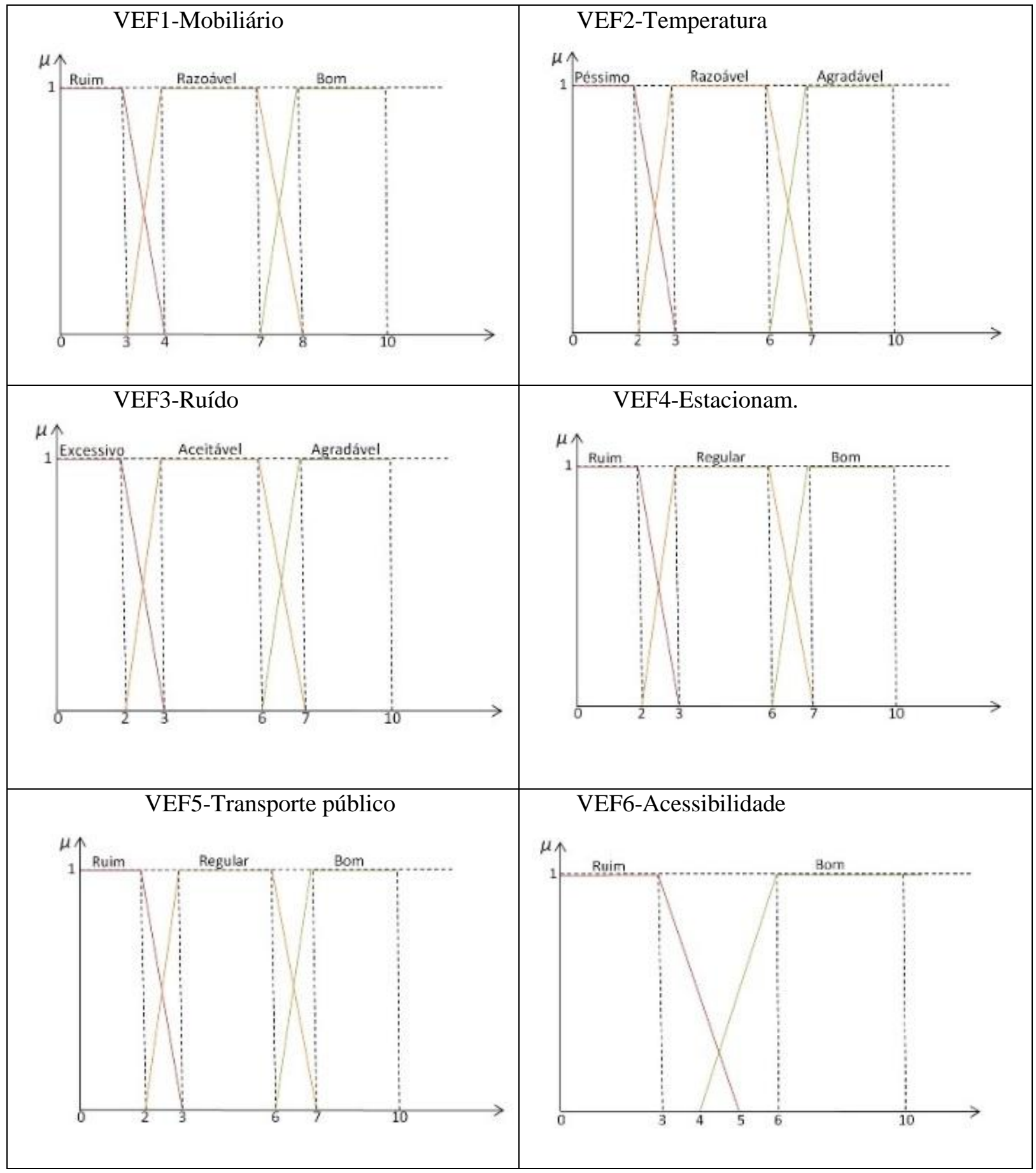




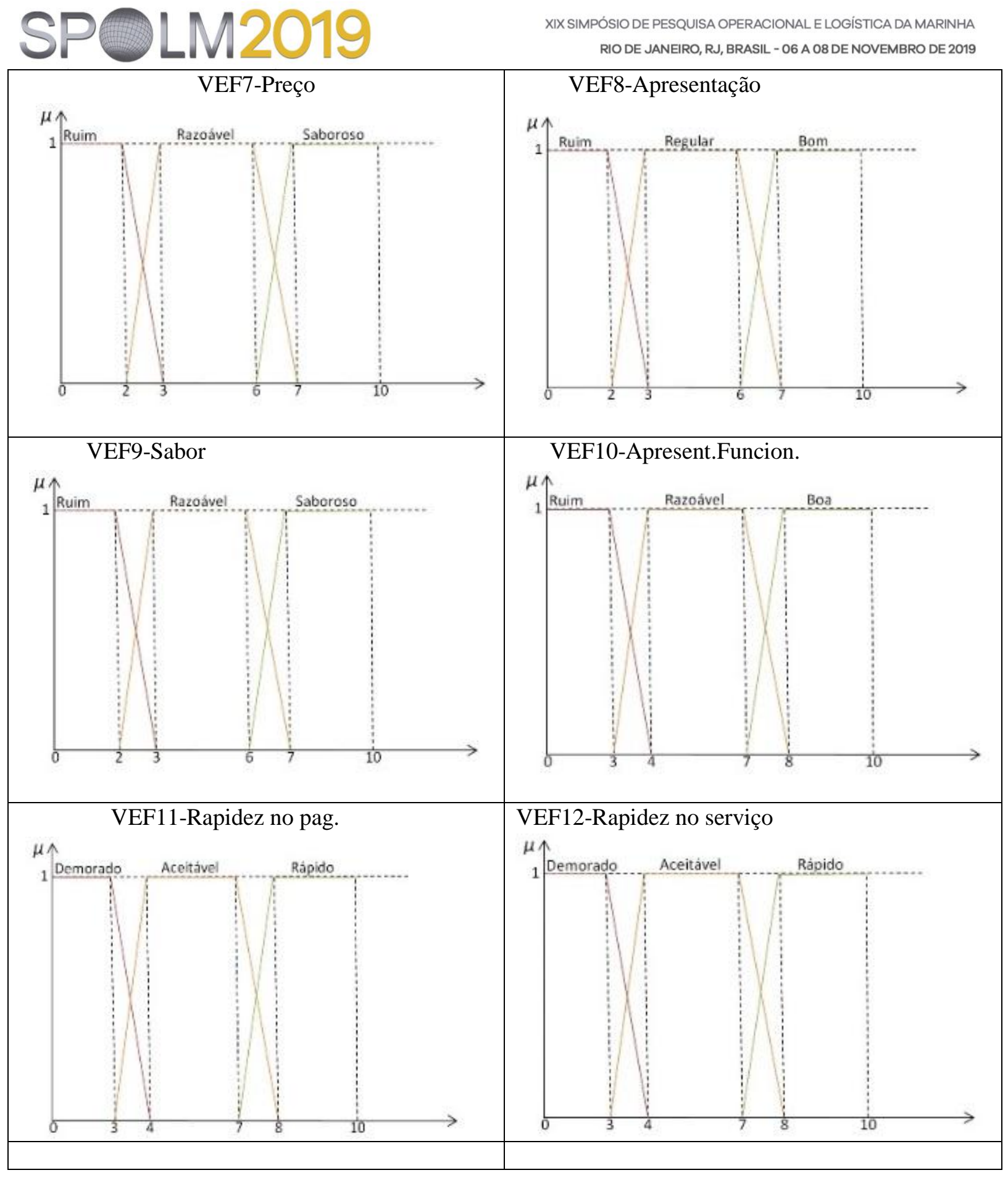

Figura 3 - Variáveis de Entrada do Modelo Fonte: Elaborada pelo autor.

O modelo é formado por uma RNA conforme apresentado na Figura 4. 


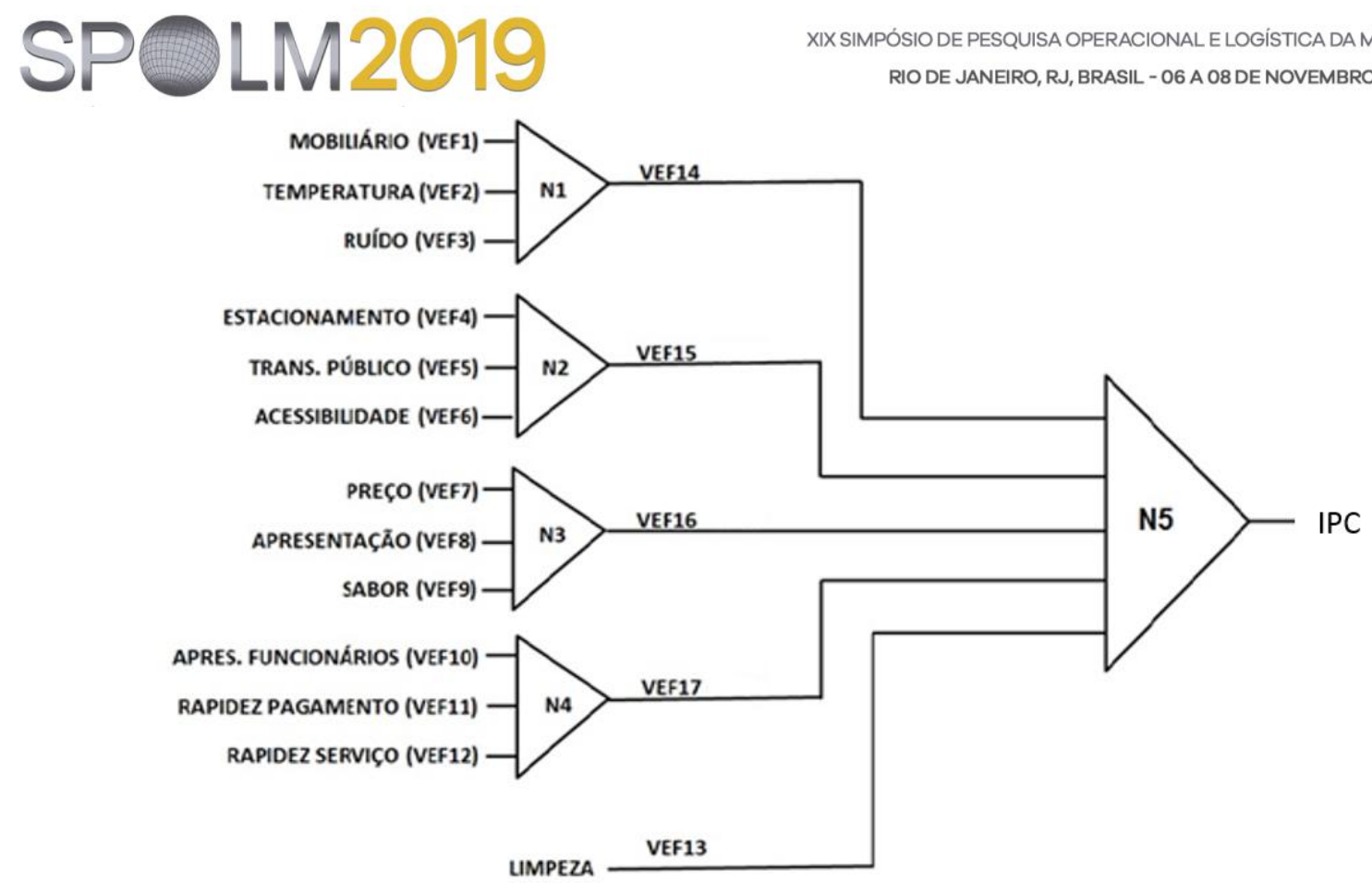

Figura 4 - RNA para geração do IPC.

Fonte: Elaborada pelo autor.

Observando-se a RNA da Figura 4, notam-se, da esquerda para direita, 12 variáveis de entrada (VEF1 a VEF12) dispostas na entrada dos neurônios artificiais N1 a N4. A variável de entrada Limpeza (VEF13) acessa o neurônio artificial final (N5) em conjunto com as variáveis de saída dos outros 4 neurônios (N1 a N4).

Desta forma, faz-se necessário modelar as 4 variáveis de saída citadas, que serão classificadas como variáveis de entrada em N5, sendo VEF14 a VEF17, onde teremos uma única saída, o indicador de percepção do cliente (IPC). Como tais variáveis têm o mesmo perfil, foram modeladas com o mesmo universo de discurso, funções de pertinência e termos linguísticos, conforme Figura 5.

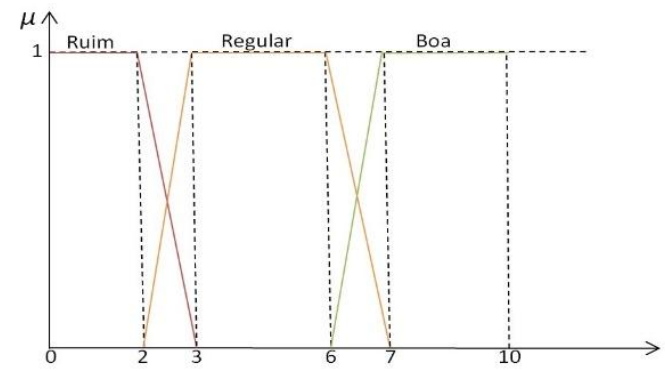

Figura 5 - Modelagem de VEF14 a VEF 17

Fonte: Elaborada pelo autor.

O estudo de caso desenvolveu-se em um restaurante "a lá carte", localizado na zona norte do Rio de janeiro, mais especificadamente em Olaria. Abriu suas portas em fevereiro de 2018, no intuito de trazer inovação no ramo gastronômico da sua localidade e resgatar proximidade com o cliente. Os dados que serviram de base para as variáveis de entrada VEF1 
a VEF13 originaram-se de uma pesquisa de satisfação realizada com os clientes do estabelecimento entre 20/09/2018 e 20/10/2018.

Para se processarem tais dados foi necessário aglutinar as respostas usando-se média aritmética $F u z z y$, redundando nos dados expostos na Tabela 2. O resultado dessa aglutinação representa.

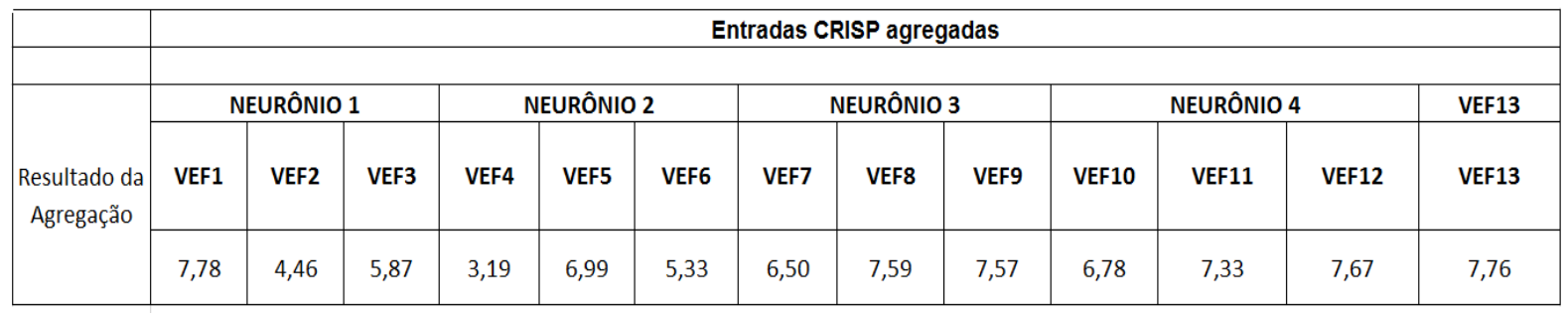

Tabela 2 - Entradas Crisp dos neurônios 1,2,3 e 4 e VEF13. Fonte: Elaborada pelo autor.

\begin{tabular}{|c|c|c|c|c|c|}
\hline \multicolumn{5}{|c|}{ Inferência (Método da Maior Possibilidade) } & \multirow[b]{2}{*}{$\begin{array}{c}\text { IPC - Defuzzyficação } \\
\text { ( Método Centro dos Máximos) }\end{array}$} \\
\hline VEF13 & VEF14 & VEF15 & VEF16 & VEF17 & \\
\hline 1,00 & 1,00 & 1,00 & 1,00 & 1,00 & 6,62 \\
\hline
\end{tabular}

Tabela 3 - Saídas Crisp dos Neurônios N1 a N5.

Fonte: Elaborada pelo autor

Inicialmente foi realizada a revisão bibliográfica abrangendo estudos relativos a avaliação e desempenho de estabelecimentos comerciais do ramo alimentício, Teoria Fuzzy, além de Redes Neurais Artificiais. Utilizou-se como base 10 artigos relacionados com as formas de avaliação de desempenho de restaurantes. A análise desses artigos resultou na escolha de treze métricas para criação do modelo matemático.

A Teoria Fuzzy e a RNA foram os métodos utilizados, pois o primeiro possibilita o processamento de variáveis qualitativas e quantitativas e o segundo se caracteriza pela possibilidade de agrupar variáveis com universo de discurso diferentes, processando-as em paralelo.

Definidas as métricas foi possível criar as variáveis de entrada Fuzzy pela modelagem dos universos de discurso, termos linguísticos e funções de pertinência que, agrupas por intermédio de cinco neurônios artificiais, ligando-os em uma RNA, permitiu a geração de indicadores parciais e do IPC (Indicador de Percepção do Cliente).

As variáveis de saída Fuzzy de cada neurônio artificial, que determinaram os indicadores parciais, e que serviram como variáveis de entrada do último neurônio, foram modeladas pelo mesmo processo relatado para as variáveis de entrada Fuzzy.

No processamento das variáveis de entrada em cada neurônio artificial são realizadas as etapas de Fuzzyficação, inferência e DeFuzzyficação. No final das etapas de processamento da RNA encontra-se um valor Crisp, o IPC, que congrega todas as variáveis de entrada e refere-se a condição do restaurante em nível de desempenho.

O modelo matemático foi implementado em aplicativo computacional Microsoft 
Excel.

Foi desenvolvido um estudo de caso pela captura de dados oriunda de pesquisa de satisfação do cliente no próprio restaurante, onde se respondia um questionário com treze perguntas, cada uma referente a uma métrica utilizada como variável de entrada Fuzzy do modelo matemático. As métricas utilizadas foram: mobiliário, temperatura, ruído, estacionamento, transporte publico, acessibilidade, preço, apresentação do prato, sabor, apresentação dos funcionários, rapidez no pagamento, rapidez no serviço e limpeza. As variáveis de saída de cada neurônio referem-se aos agrupamentos das variáveis de entrada, e foram classificadas como Conforto, Acesso, Refeição e Atendimento.

Os valores obtidos por meio do estudo de caso, quando analisados numa escala de 0 à 10 , sendo 0 para a pior situação e 10 a melhor, demonstraram que a percepção do cliente em relação ao estabelecimento estudado é positiva. Ainda que relevante, tal resultado deve ser interpretado com cautela, pois podem representar a realidade do restaurante em um determinado espaço de tempo que foi representado pela resposta de alguns clientes.

Foi possível também constatar que para melhores ajustes lineares, principalmente no aumento do valor do IPC, será preciso tomar medidas gerenciais nas seguintes variáveis: VEF2, VEF4, VEF6.

Sendo assim, para o crescimento da VEF2, por exemplo, será necessária a troca do ar condicionado utilizado atualmente por dois de menor potência, viabilizando melhor distribuição da temperatura no ambiente.

Para VEF4 denota a necessidade que os gestores busquem estacionamento privado próximo, para melhor atender aos clientes.

No caso da VEF6 foi aconselhada a construção de uma rampa para portadores de deficiência e uma mesa adequada para poder melhor atender a chegada dos clientes em geral.

Após tais melhorias, se realizada nova pesquisa de satisfação, usando esses dados no modelo matemático, se poderá obter um IPC ainda melhor.

Com os resultados provenientes das avaliações de desempenho que deverão ser realizadas periodicamente, consegue-se ter o acompanhamento da percepção do cliente em relação ao estabelecimento ao longo do tempo, formando série histórica, permitindo ações para continuidade do bom atendimento e da qualidade do serviço. 


\section{REFERÊNCIAS BIBLIOGRÁFICAS}

[1] MORAES, Daniel. A arte da fidelização do cliente: entenda o que você precisa para ter um consumidor que propague sua marca. Revista digital Rock Content. Belo Horizonte MG, outubro de 2017.

[2] ZADEH, L. (1965). Fuzzy Sets, Information and Control 8: 338-353.

[3] AZEVEDO, Kellen Guimaraes; COSTA, Natalia rodrigues; FREITAS, Andre Luis Policani. Avaliação da qualidade dos serviços de um restaurante universitário: Uma análise utilizando métodos de apoio à decisão. Desenvolvimento em questão, Fortaleza 2015.

[4] BALEEIRO, Gleimar Botelho. Modelagem Neuro-Fuzzy na estimativa de volume de Eucalyptus. Minas Gerais, 2007.

[5] RODRIGUES, Nayara dos Santos. Excelência no atendimento: como a comunicação influencia na qualidade do atendimento. Universidade Federal de Juiz de Fora Faculdade De Comunicação. Juiz de Fora, 2016.

[6] SILVA, Romeu Soares. Atuação das empresas no mercado de baixa renda: desenvolvimento e transformação social. São Paulo, 2009.

[7] BRAGA, Ana Carolina; PEREIRA, Tafael de Lucas; JUNIOR, Pedro Paulo de Andrade. Avaliação de restaurante universitário por meio de indicadores de qualidade.

Desenvolvimento em questão, Santa Catarina, v.13, n.30, p.306-326, abri./jun.2015.

[8] BERG, Ernesto. Você conhece seu cliente? Nem sempre. Disponível em: http://www.administradores.com.br/artigos/marketing/voce-conhece-mesmo-seu-clientenem-sempre/108988/. Acessado em 05 de maio de 2018.

[9] JUNIOR, Ricardo Cestari. Os 5 pilares que garantem a qualidade no atendimento ao cliente. Blog NeoAssit. São Paulo, maio, 2016.

[10] BORTOLUZZI, Sandro César; TAZINASSO, Luciane. Avaliação de desempenho em pequenas empresas comerciais: estudo de Caso em uma empresa de combustíveis. Revista Ciências Sociais em Perspectiva, Paraná, v. 11, n. 20 - 1 Semestre de 2012.

[11] CABRAL, Amanda. Excelência no Atendimento junto ao mercado competitivo. Disponível em: http://www.rhportal.com.br/artigos-rh/excelncia-no-atendimento-junto-aomercado-competitivo. Acessado em 05 de maio de 2018.

[12] COSTA, Ariana de Souza Carvalho; SANTANA, Lídia Chagas; TRIGO, Antônio Carrera. Qualidade do atendimento ao cliente: Um grande diferencial competitivo para as organizações. Revista de Iniciação Científica - RIC Cairu. v. 02, nº 02, p. 155-172. Salvador, junho 2015.

[13] DEMOLINARI, Natasha Granato. Avaliação da qualidade percebida e definição de ações de melhoria: Um estudo de caso em um restaurante do Sudeste de Minas Gerais. Juiz de Fora, 2014.

[14] FURTADO, Leonardo. Diagnostico da qualidade dos serviços oferecidos pelo restaurante recanto da sereia no município de Itapema/SC. Balneário Camboriú, 2008.

[15] GIL, Antônio Carlos. Métodos e Técnicas de Pesquisa Social. $6^{\text {a }}$ Edição. Editora Atlas S.A, 2008. São Paulo, SP.

[16] GARCEZ, Eliane M.S; FACHIN, Gleusy R.B; JUNIOR, Pedro Andrade. Indicadores da qualidade em restaurante: Um estudo de caso. Santa Catarina, 2000.

[17] GOLEMAN, Daniel. A qualidade no atendimento ao cliente com fator de crescimento empresarial. Araguaína, março 2016. Disponível em: http://www.administradores.com.br/artigos/academico/a-qualidade-no-atendimento-aocliente-como-fator-de-crescimento-empresarial/100507. Acessado em 07 de maio de 2018. 
[18] GOMIDE, Fernando A.C, GUDWIN, Ricardo. R, TANSCHEIT, Ricardo. Conceitos fundamentais da teoria de conjuntos Fuzzy, lógica Fuzzy e aplicações. São Luiz/ MA, 2014.

[19] GONÇALVES, André Paim. Aplicação de Lógica Fuzzy em Guerra Eletrônica. Disponível em: http://www.sige.ita.br/anais/IXSIGE/Artigos/AO_07.pdf. Acessado em 01 de agosto de 2018.

[20] MOURA, T. L., ALLIPRANDINI, D. H. Determinantes da Qualidade em Serviços de Alimentação: O Caso das Empresas de Refeições Coletivas. XXIV Encontro Nacional de Eng. De Produção - Florianópolis, SC, Brasil, 03 a 05 de Nov., 2004.

[21] WOLFF, Paulo Roberto. Construindo um modelo de avaliação de um restaurante no ramo de fast-food: um estudo de caso. Florianópolis - SC, fev. 2005.

[22] SAVOT, Ricardo Barz. Uma abordagem híbrida baseada em casos e redes neurais. Uma aplicação: Escolha e configuração de modelos de redes neurais. Instituto de Ciências, matemática e de computação. São Carlos - SP, 07 de mar. 2002. Disponível em: https://www.unilestemg.br/principiumonline/publicacoes/.../152_168_redes_neuro.pdf. Acessado em 03 de Agosto de 2018.

[23] SEKIYA, Tiago Satoci. Desenvolvimento de sistema de indicadores para um restaurante. São Paulo, 2013.

[24] SILVA, Naico Líneque Pontes. Atendimento a clientes: o marketing de relacionamento. João Pessoa - PB, jun. 2010. Disponível em: http://www.administradores.com.br/artigos/marketing/atendimento-a-clientes-omarketing-de-relacionamento/45961.Acessado em: 28 de abril de 2018.

[25] OLIVEIRA, Daniel Canavese. Elaboração de modelos linguísticos baseados na teoria de conjuntos fuzzy para mensuração de qualidade de vida relacionada à saúde.

Universidade Federal do Rio de Janeiro, Faculdade de Medicina, Departamento de Medicina Preventiva. Rio de janeiro, fevereiro 2004.

[26] SOUZA, Osmar. Introdução à Teoria dos Conjuntos Fuzzy. Teoria e Aplicações de Memórias Associativas Morfológicas Nebulosas. Londrina, 2010.

[27] SHICA, J. P. M; ALBUQUERQUE, Neto; SANTANA, M. V; PAZ, J.S; Araújo W.B. Avaliação do nível de satisfação dos usuários de um restaurante universitário: o caso de uma instituição publica de ensino. Rio grande do Norte, 2016.

[28] TINOCO, Maria Auxiliadora; RIBEIRO, José Luiz. Estudo qualitativo dos principais atributos que determinam a percepção de qualidade dos consummidores de restaurant a la carte. Gest. Prod., São Carlos, v. 15, n. 1, p. 73-87, jan.-abr. 2007.

[29] ORTEGA, Neli Regina Siqueira. Aplicacão da Teoria de Conjuntos Fuzzy a Problemas da Biomedicina, São Paulo, 2001. Disponível em: https://www.ime.usp.br/ tonelli/verao-fuzzy/neli/principal.pdf. Acessado em: $02 \mathrm{de}$ agosto de 2018.

[30] AZEVEDO, Kellen Guimaraes; COSTA, Natalia Rodrigues; FREITAS, Andre Luis Policani. Avaliação da qualidade dos serviços de um restaurante universitário: Uma análise utilizando métodos de apoio à decisão. Desenvolvimento em questão, Fortaleza 2015.

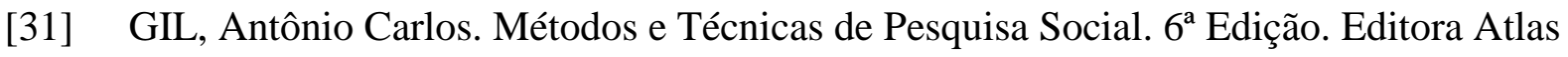
S.A, 2008. São Paulo, SP. 